\title{
Mycobacterium heckeshornense Lung Infection that was Diagnosed as Mycobacterium xenopi Disease by DNA-DNA Hybridization (DDH)
}

\author{
Kozo Morimoto ${ }^{1}$, Yuko Kazumi ${ }^{2}$, Shinji Maeda ${ }^{2}$, Kozo Yoshimori ${ }^{1}$, Takashi Yoshiyama ${ }^{1}$, \\ Hideo Ogata ${ }^{1}$, Atsuyuki Kurashima ${ }^{1}$ and Shoji Kudoh ${ }^{1}$
}

\begin{abstract}
The DNA sequencing analyses of the 16S rRNA gene, rpoB and hsp65 were conducted to characterize six strains that had been identified as Mycobacterium xenopi by DNA-DNA hybridization (DDH) for past ten years in our hospital. The results revealed Mycobacterium heckeshornense infection in one of the six cases. A 47-year-old man, who had been treated for pneumonia, had pulmonary nontuberculous mycobacterial disease. The sputa from the patient were culture positive for mycobacterium in three times. And it was diagnosed as M. xenopi by DDH method. Chest X-ray showed fibrocavitary lesion in right upper lobe was successfully treated with clarithromycin for four weeks.
\end{abstract}

Key words: Mycobacterium heckeshornense, Mycobacterium xenopi, DNA-DNA hybridization

(Intern Med 50: 1251-1253, 2011)

(DOI: 10.2169/internalmedicine.50.4628)

\section{Introduction}

Since Roth et al reported the first case of Mycobacterium heckeshornense in 2000 (1), reports of its infection have been frequently published. There were three case reports of pulmonary disease and one case of tenosynovitis, lymphadenitis and lumbar spondylodiskitis (2-6). M. heckeshornense is a scotochromogenic and slowly growing organism, having similar properties to Mycobacterium xenopi. In recent years, of a new technique has been developed for bacterial analyses, such as DNA sequencing analyses of the genes in the $16 \mathrm{~S}$ rRNA, rроB and $h s p 65$. Their analyses have led to the identification of numerous new bacterial strains. M. heckeshornense is one such example. It is important to clarify the clinical differences between the previously diagnosed strain and newly identified strain.

\section{Case Report}

A 47-year-old man was admitted to our hospital with pneumonia in December 2005. The patient had no past history of any significant illnesses, including chronic obstructive pulmonary disease. He had smoked about 30 cigarettes a day for 20 years. Serological tests for human immunodeficiency virus infection were negative. Chest X-ray (CXR) showed consolidation of the right upper lobe (RUL). The patient was treated with sulbactam sodium/ampicillin sodium (SBT/ABPC) for 5 days. Although a positive result of acid-fast bacteria was obtained two times in a row, no therapy was initiated, because the clinical presentation was consistent with community-acquired pneumonia and the PCR tests for both Mycobacterium tuberculosis (TB) and Mycobacterium avium complex were negative. After the patient was discharged from the hospital, the culture for mycobacterium was still positive. The DNA-DNA hybridization test (DDH mycobacteria, Kyokuto, Japan) identified that the mycobacterium was M. xenopi. Five months later, in May 2006, the patient was hospitalized with pneumonia again. Chest computed tomography (CT) revealed both the opacity in the right middle lobe and a fibrocavitary lesion in the RUL. Treatment with meropenem (MEPM) was started, and

${ }^{1}$ Fukujuji Hospital, Japan Anti-tuberculosis Association, Japan and ${ }^{2}$ The Research Institute of Tuberculosis, Japan Anti-Tuberculosis Association, Japan

Received for publication October 3, 2010; Accepted for publication February 8, 2011

Correspondence to Dr. Kozo Morimoto, bxypb621@ybb.ne.jp 
4 days later it was changed to moxifloxacin. Smears test of sputum were negative for acid-fast bacteria. However, the mycobacterial culture test was positive and $M$. xenopi was identified again. When two weeks passed after discharge from hospital, the CXR showed improvement of opacity in the right middle lobe, and the persistent fibrocavitary lesion. He complained of persistent cough, and he was treated with clarithromycin for 4 weeks. His symptoms were resolved, and the CXR showed improvement of the cavitary lesion. The mycobacterial culture test has been negative for 2 years since then.

\section{Discussion}

In the current cases of $M$. heckeshornense disease, refractory pulmonary diseases have been reported. The percentage of the $M$. heckeshornense patients with extrapulmonary lesions might be high in comparison with other nontuberculous mycobacterial (NTM) diseases. In the case of pulmonary disease, fibrocavitary formation was observed in three of four cases, including the present case that was similar to the disease pattern observed in M. xenopi infection. According to the first report of $M$. heckeshornense, it was resistant to isoniazid, and susceptible to rifampicin, amikacin, clarithromycin, ethambutol and ciprofloxacin (1). In the present case, the isolate was sensitive to isoniazid, rifampicin, ethionamide, cycloserine, levofloxacin and clarithromycin. The phenotype of drug susceptibity to isoniazid was different between the reference strain and the isolate. On the other hand, M. xenopi usually shows susceptibility to aminoglycosides and ethionamide, but is not always susceptible to the first-line antituberculous drugs (7). British Thoracic Society (BTS) recommends using rifampicin and ethambutol for treatment of $M$. xenopi as the first-line drugs. However, the treatment results of $M$. xenopi infection have been disappointing.

Although only four cases of pulmonary disease caused by M. heckeshornense have been reported until date, first-line antituberculous drugs were used in three cases because the phenotype of this organism was similar to M. xenopi. $M$. heckeshornense might be susceptible to other drugs including the new macrolides because clarithromycin was effective for treatment in our $M$. heckeshornense case and the previous case, a 65-year-old woman, was susceptible to those drugs (4). Therefore, when bacilli are identified as $M$. heckeshornense, we can have some choices of drugs in disease treatment. There have been two cases of pulmonary disease, so far as we know in Japan (8). One is a 51-year-old woman who showed progressive pulmonary disease and died after suffering from the disease for 14 years, and the other is a 72 year-old-man with pneumoconiosis. In this case, smear was positive in a total of 9 times and culture was positive in a total of 8 times within 2 months. However, the patient recovered and became smear- and culture-negative without any treatment. The highlights of this case are the fact that this organism does not always invade the lung tis- sues and might occur in the nature of a contaminant.

In Japan, NTM are identified by DDH method when TB is negative. The bacterial strain can be identified within several hours by measurement of the similarity between the specimen material DNA and 18 standard DNAs fixed to a 96-well plate. This method is based on the suggestion of modern taxonomic guidelines that homology among individual independent species should be less than $70 \%$ in optimal conditions, and has been available in Japan since 1980. Using sequence analyses of $16 \mathrm{~S}$ rRNA gene, rpoB and $h s p 65$, we attempted to characterize six strains that had been identified as $M$. xenopi by DDH in the past ten years in our hospital. In one of six cases, the strain was found to be $M$. heckeshornense. The differences of nucleotides between $M$. xenopi (the standard strain from American Type Culture Collection) and $M$. heckeshornense (our isolate) in genes of $16 \mathrm{~S}$ rRNA, rpoB and hsp65 were $24 \mathrm{bp}$ in $448 \mathrm{bp}, 1 \mathrm{bp}$ in $306 \mathrm{bp}$ and 8 bp in $419 \mathrm{bp}$, respectively (9-11). The DNA sequences in their genes between the standard strain of $M$. heckeshornense and our isolate were identical. We found that sequence analyses are powerful tools for identification of mycobacterial strains in the clinical setting.

Although $M$. xenopi disease is rare in Japan, it is suggested that patients infected with $M$. heckeshornense may have been included at a constant rate in the cases that were diagnosed as $M$. xenopi disease by DDH. Therefore, careful attention to this point is necessary in the future in Japan.

The authors state that they have no Conflict of Interest (COI).

\section{References}

1. Roth A, Reischl U, Schonfeld N, et al. Mycobacterium heckeshornense sp. nov., a new pathogenic slowly growing Mycobacterium sp. causing cavitary lung disease in an immunocompetent patient. J Clin Microbiol 38: 4102-4107, 2000.

2. van Hest R, van der Zanden A, Boeree M, et al. Mycobacterium heckeshornense infection in an immunocompetent patient and identification by $16 \mathrm{~S}$ rRNA sequence analysis of culture material and a histopathology tissue specimen. J Clin Microbiol 42: 43864389, 2004.

3. Godreuil S, Marchandin H, Terru D, et al. Mycobacterium heckeshornense tenosynovitis. Scand J Infect Dis 38: 1098-1101, 2006.

4. Jaureguy F, Ioos V, Marzouk P, et al. Mycobacterium heckeshornense: an emerging pathogen responsible for a recurrent lung infection. J Infect 54: e33-e35, 2007.

5. Elyousfi AA, Leiter JR, Goytan MJ, Robinson DB. Mycobacterium heckeshornense lumbar spondylodiskitis in a patient with rheumatoid arthritis receiving etanercept treatment. J Rheumatol 36: 2130-2131, 2009.

6. McBride SJ, Taylor SL, Pandey SK, Holland DJ. First case of $M y$ cobacterium heckeshornense lymphadenitis. J Clin Microbiol 47: 268-270, 2009.

7. Varadi RG, Marras TK. Pulmonary Mycobacterium xenopi infection in non-HIV-infected patients: a systematic review. Int $\mathrm{J}$ Tuberc Lung Dis 13: 1210-1218, 2009.

8. Kazumi Y, Sugawara I, Wada M, Kimura K, Itono H. Microbiologically identified isolates of Mycobacterium heckeshornense in two patients. Kekkaku 81: 603-607, 2006 (in Japanese).

9. Turenne CY, Tschetter L, Wolfe J, Kabani A. Necessity of quality- 
Intern Med 50: 1251-1253, 2011 DOI: 10.2169/internalmedicine.50.4628

controlled 16S rRNA gene sequence databases: identifying nontuberculous Mycobacterium species. J Clin Microbiol 39: 36373648, 2001.

10. Kim BJ, Lee SH, Lyu MA, et al. Identification of mycobacterial species by comparative sequence analysis of the RNA polymerase gene (rpoB). J Clin Microbiol 37: 1714-1720, 1999.
11. Telenti A, Marchesi F, Balz M, Bally F, Böttger EC, Bodmer T. Rapid identification of mycobacteria to the species level by polymerase chain reaction and restriction enzyme analysis. J Clin Microbiol 31: 175-178, 1993.

(C) 2011 The Japanese Society of Internal Medicine http://www.naika.or.jp/imindex.html 